\title{
Structure-Conductivity Relationships of Block Copolymer Membranes based on Hydrated Protic Polymerized Ionic Liquids: Effect of Domain Spacing - Supporting Information
}

Gabriel E. Sanoja, ${ }^{1,2,4}$ Bhooshan C. Popere, ${ }^{4}$ Bryan S. Beckingham, ${ }^{2}$ Christopher M. Evans, ${ }^{4}$ Nathaniel A. Lynd, ${ }^{* 2,3}$ and Rachel A. Segalman ${ }^{*, 4,5}$

${ }^{1}$ Department of Chemical and Biomolecular Engineering, University of California, Berkeley, California 94720, United States

${ }^{2}$ Joint Center for Artificial Photosynthesis, Lawrence Berkeley National Laboratory, Berkeley, California 94720, United States

${ }^{3}$ McKetta Department of Chemical Engineering, University of Texas, Austin, Texas 78712 , United States

${ }^{4}$ Department of Chemical Engineering, University of California, Santa Barbara, California 93106, United States

${ }^{5}$ Materials Department, University of California, Santa Barbara 93106, United States

*Email: segalman@engineering.ucsb.edu (R.A.S) and 1ynd@che.utexas.edu (N.A.L) 


\section{Molecular Characterization of PS- $b$-PB}

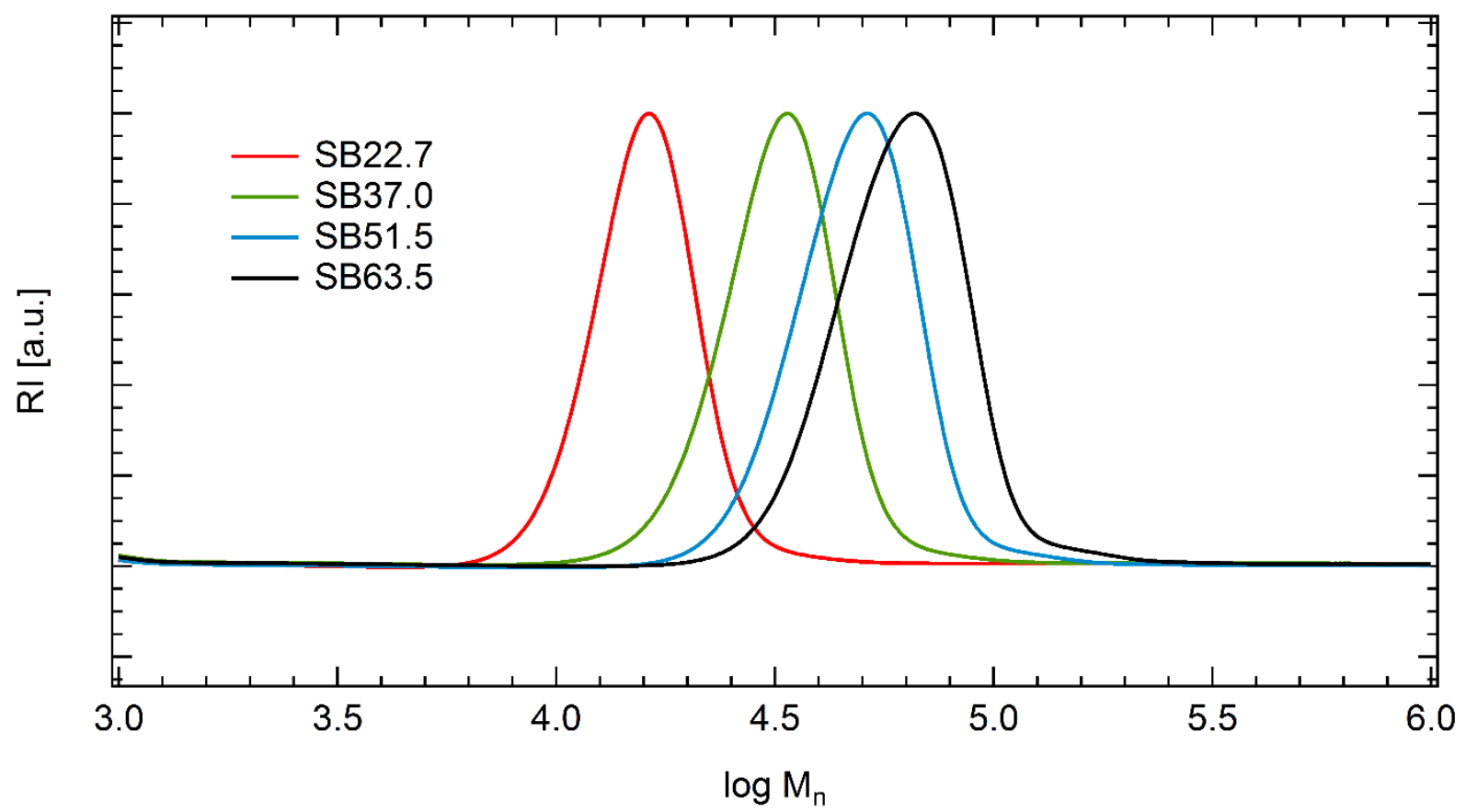

Figure S1: Gel Permeation Chromatography of PS- $b$-PB calibrated against polystyrene standards. The polydispersity $(\mathrm{PDI}=$ $\mathrm{M}_{\mathrm{w}} / \mathrm{M}_{\mathrm{n}}$ ) was lower than 1.2 in the block copolymers synthesized. This is consistent with the living nature of the sequential anionic polymerization of styrene and butadiene.

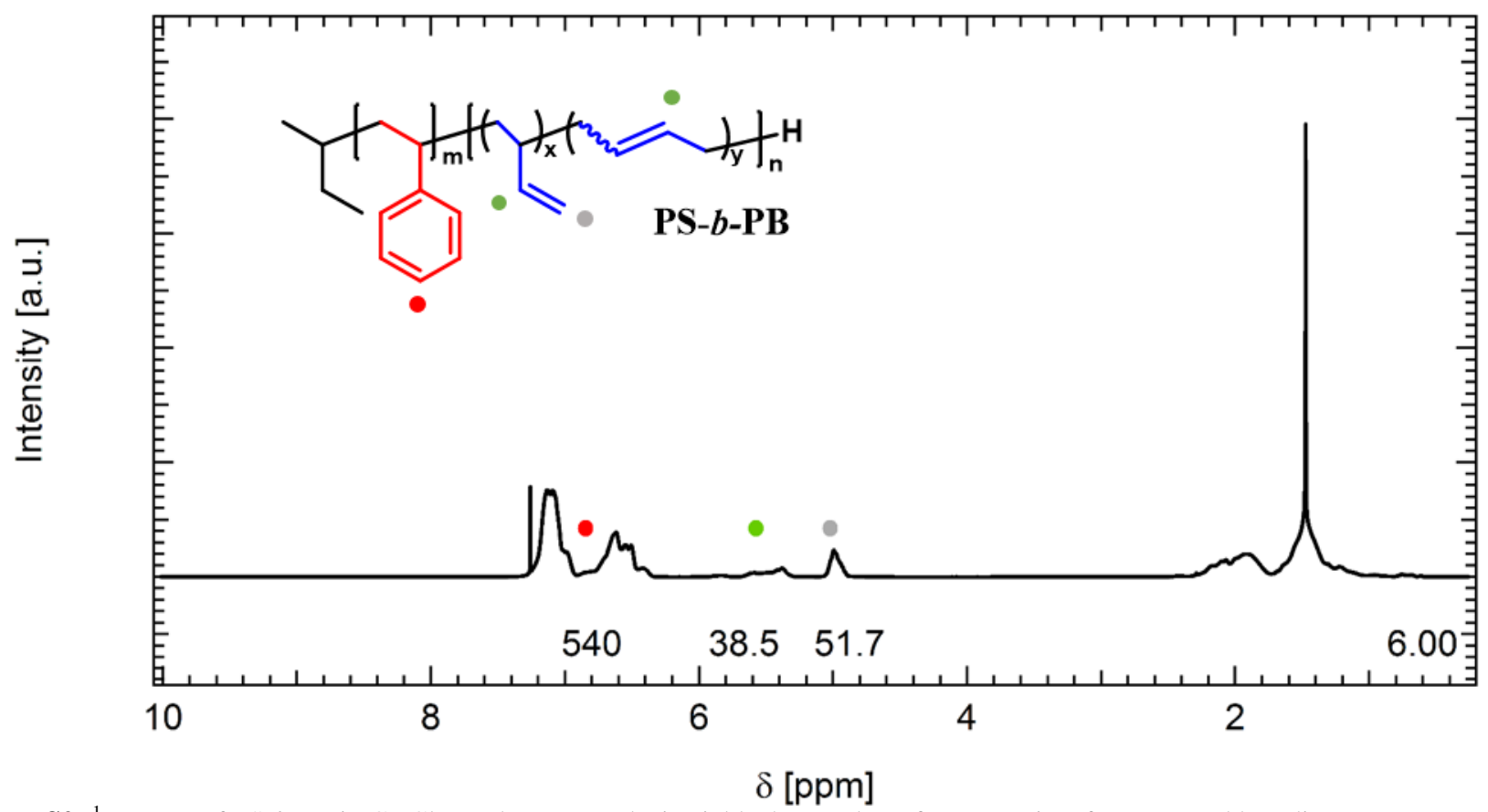

Figure S2: ${ }^{1} \mathrm{H}$ NMR of PS- $b$-PB in $\mathrm{CDCl}_{3}$. End-group analysis yields the number of repeat units of styrene and butadiene. 


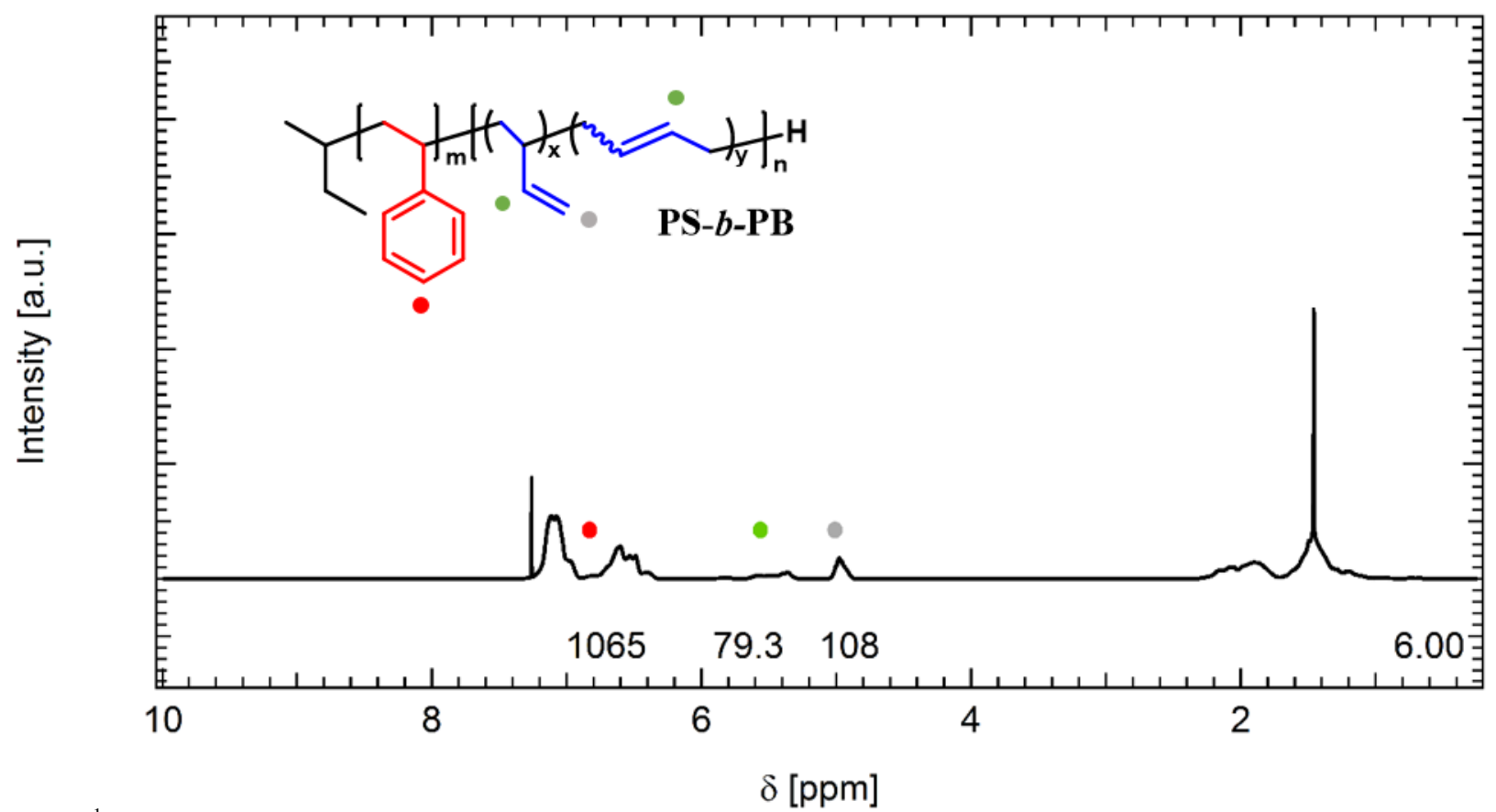

Figure S3: ${ }^{1} \mathrm{H}$ NMR of PS- $b$-PB in $\mathrm{CDCl}_{3}$. End-group analysis yields the number of repeat units of styrene and butadiene.

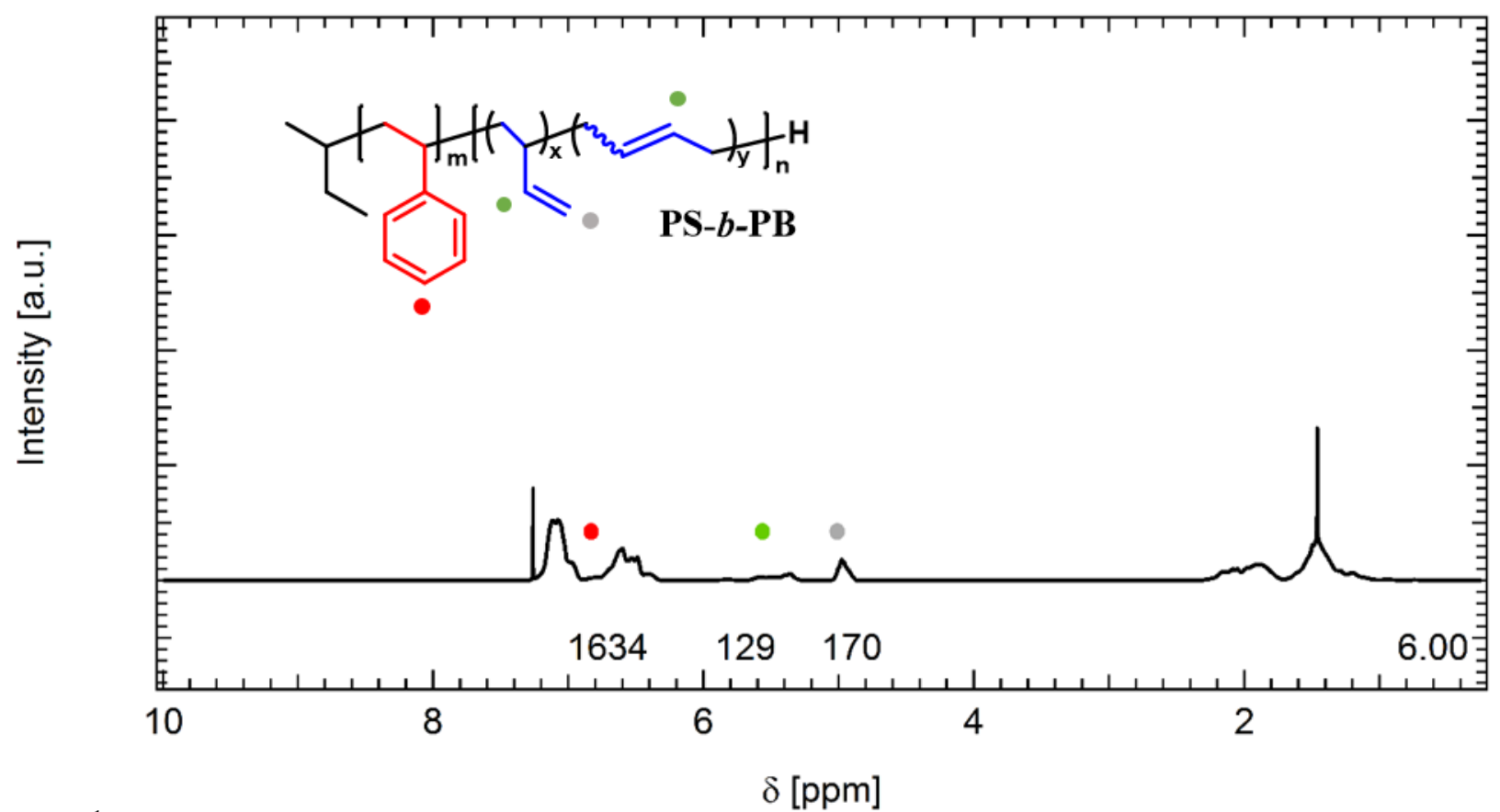

Figure S4: ${ }^{1} \mathrm{H}$ NMR of PS-b-PB in $\mathrm{CDCl}_{3}$. End-group analysis yields the number of repeat units of styrene and butadiene. 


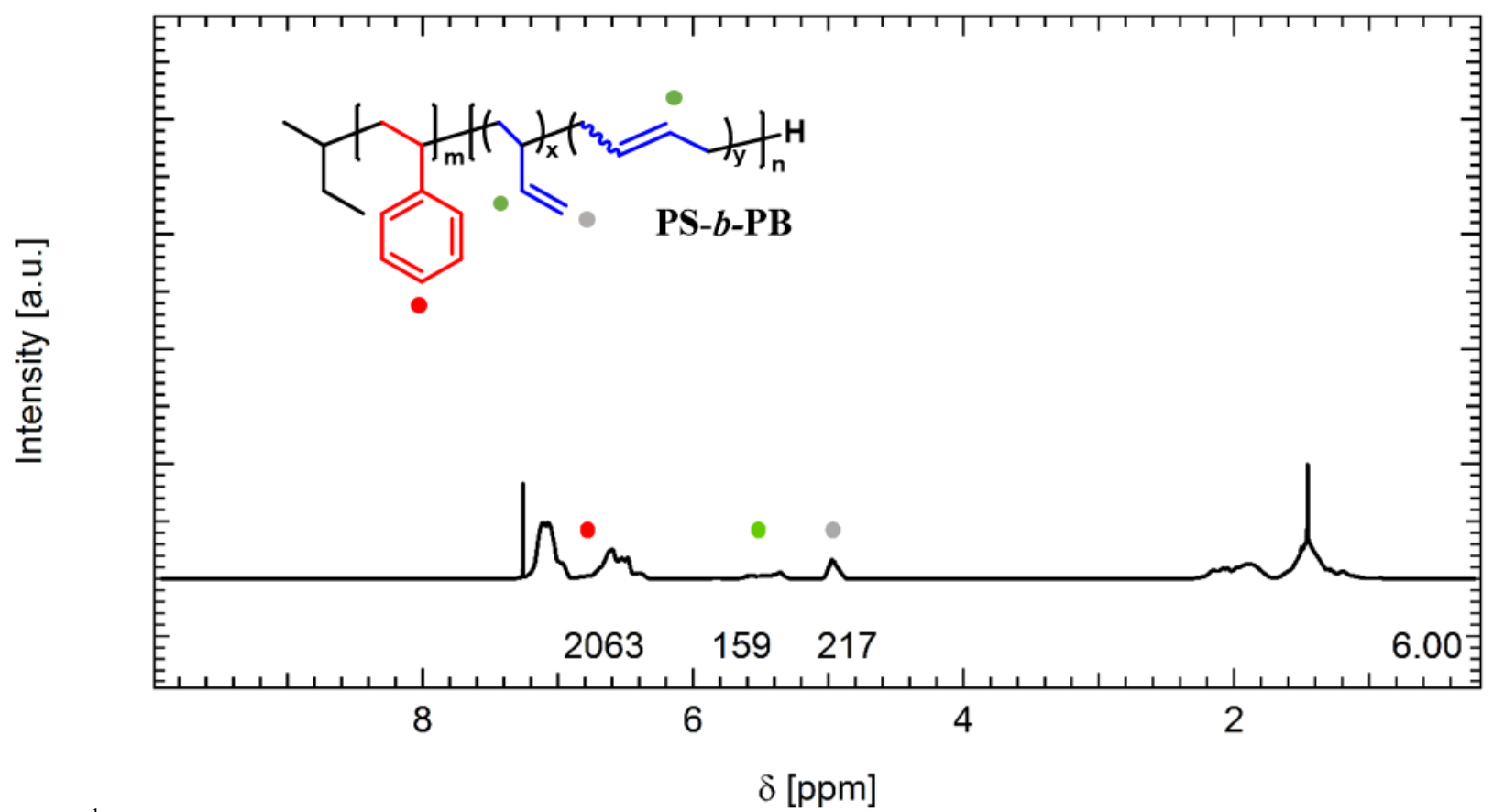

Figure S5: ${ }^{1} \mathrm{H}$ NMR of PS-b-PB in $\mathrm{CDCl}_{3}$. End-group analysis yields the number of repeat units of styrene and butadiene.

Table S1: Properties of PS-b-PB as determined from ${ }^{1} \mathrm{H}$ NMR

$\begin{array}{cccccc}\text { Polymer }^{\mathrm{a}} & \mathrm{N}_{\mathrm{S}} & \mathrm{N}_{\mathrm{B}-1,2} & \mathrm{~N}_{\mathrm{B}-1,4} & \% 1,2 & \mathrm{M}_{\mathrm{n}}(\mathrm{kg} / \mathrm{mol}) \\ \text { SB22.7 } & 108 & 26 & 6 & 81.3 & 12.98 \\ \text { SB37.0 } & 213 & 54 & 13 & 80.6 & 25.81 \\ \text { SB51.5 } & 327 & 85 & 22 & 79.4 & 39.84 \\ \text { SB63.5 } & 413 & 109 & 25 & 81.3 & 50.26\end{array}$

${ }^{a}$ Polymers are labeled SBXX.X, where XX.X is the lamellar domain spacing in nm of hydrated PS- $b$-PIL membranes at room temperature derived from the corresponding PS- $b$-PB precursor. 
Molecular Characterization of His-SH

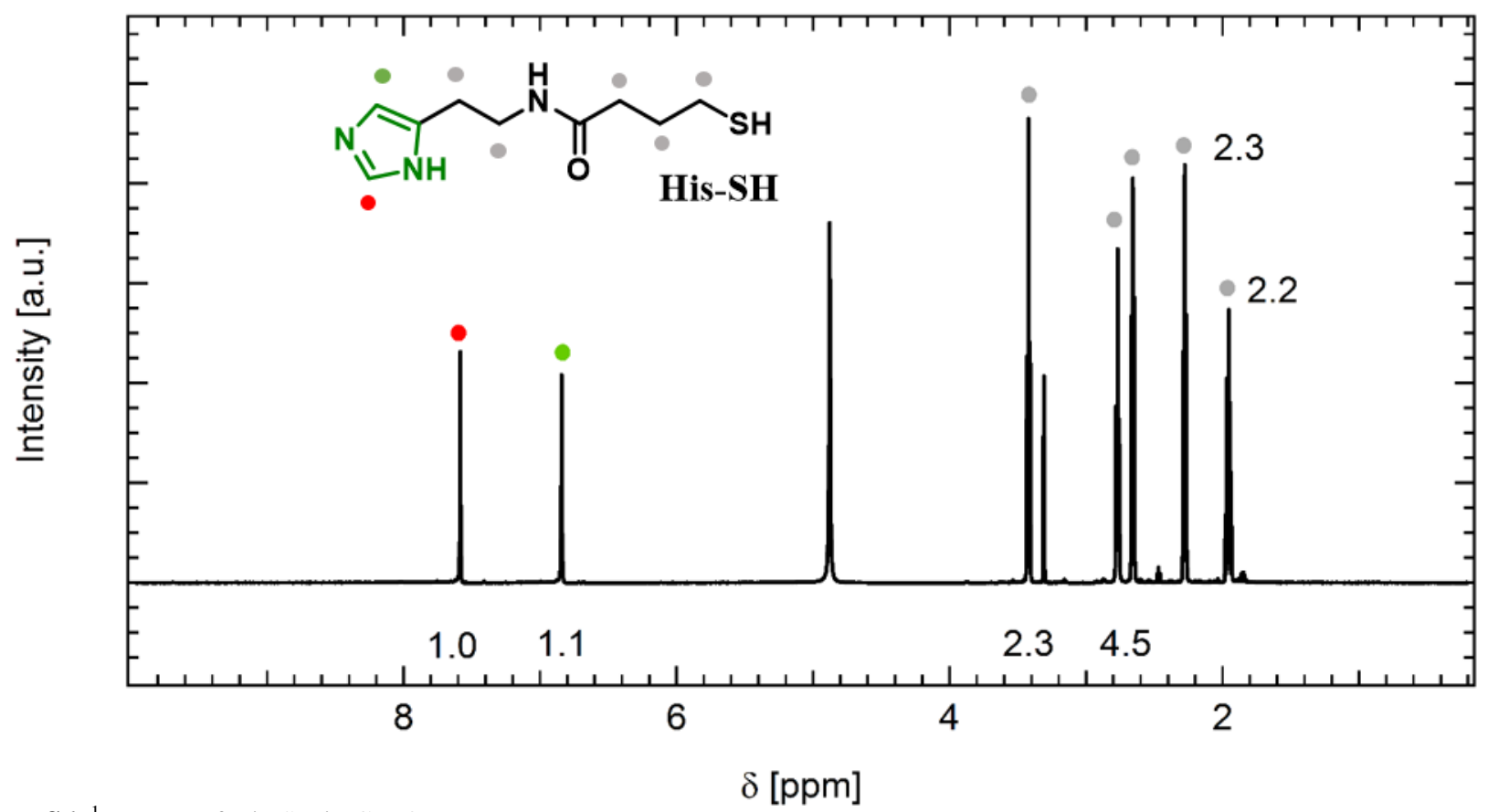

Figure S6: ${ }^{1} \mathrm{H}$ NMR of His-SH in $\mathrm{CD}_{3} \mathrm{OD}$.

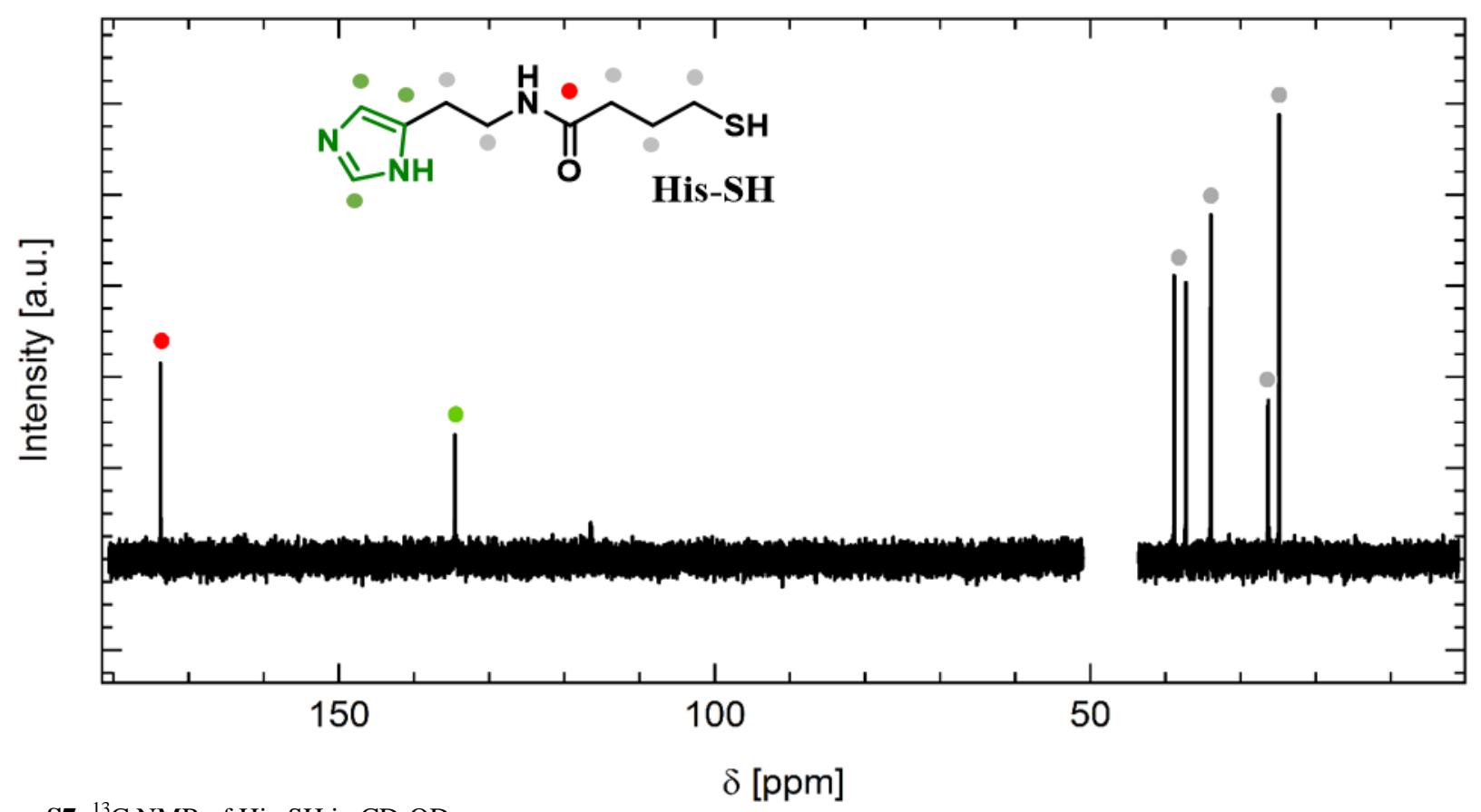

Figure S7: ${ }^{13} \mathrm{C}$ NMR of His-SH in $\mathrm{CD}_{3} \mathrm{OD}$. 


\section{Molecular Characterization of PS- $b$-PH}

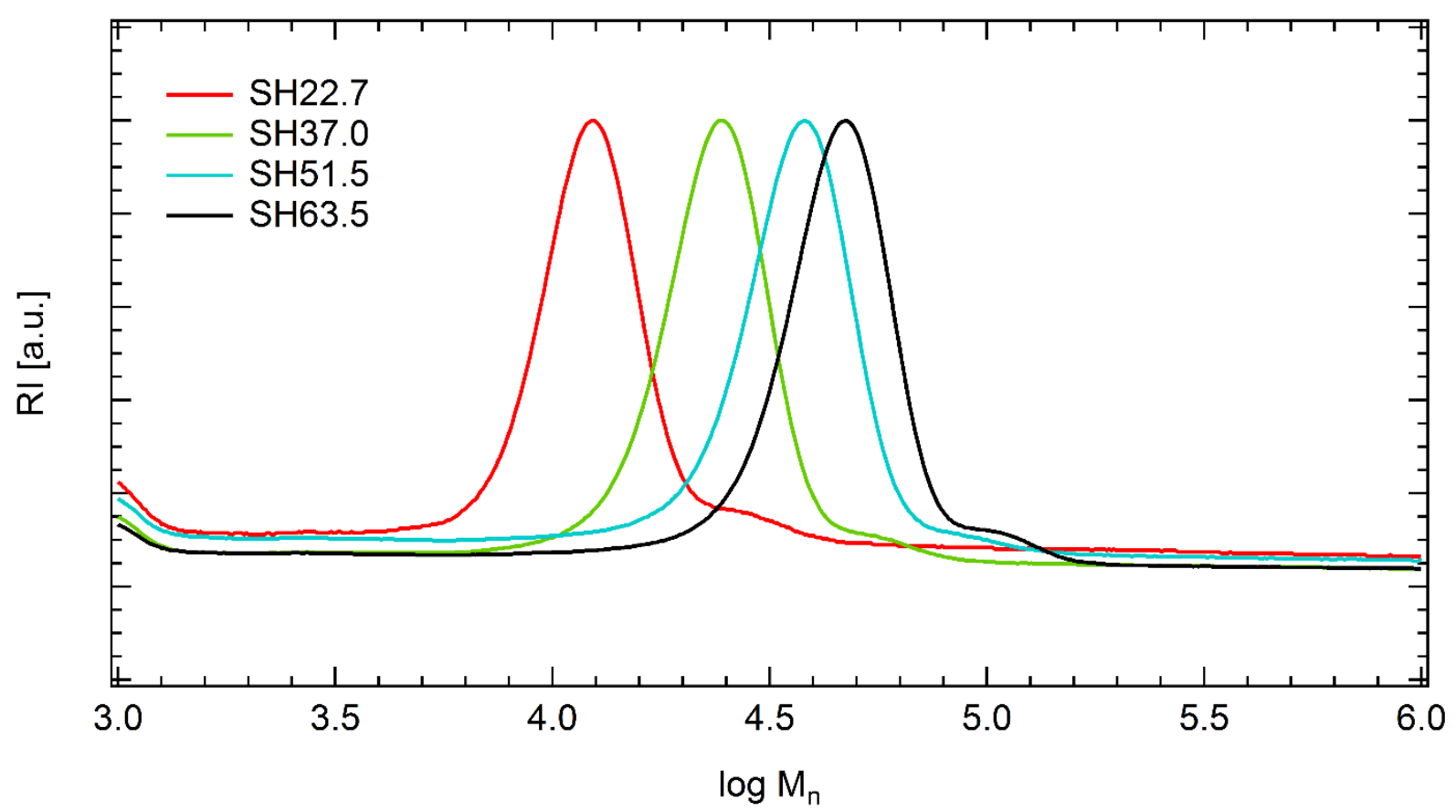

Figure S8: Gel Permeation Chromatography of PS-b-PH calibrated against polystyrene standards. The polydispersity (PDI = $\mathrm{M}_{\mathrm{w}} / \mathrm{M}_{\mathrm{n}}$ ) was lower than 1.2 in the block copolymers synthesized. The absence of a significant coupling peak demonstrates that no cross-linking occurs in the functionalization of PS-b-PB with His-SH vial thiol-ene click chemistry.

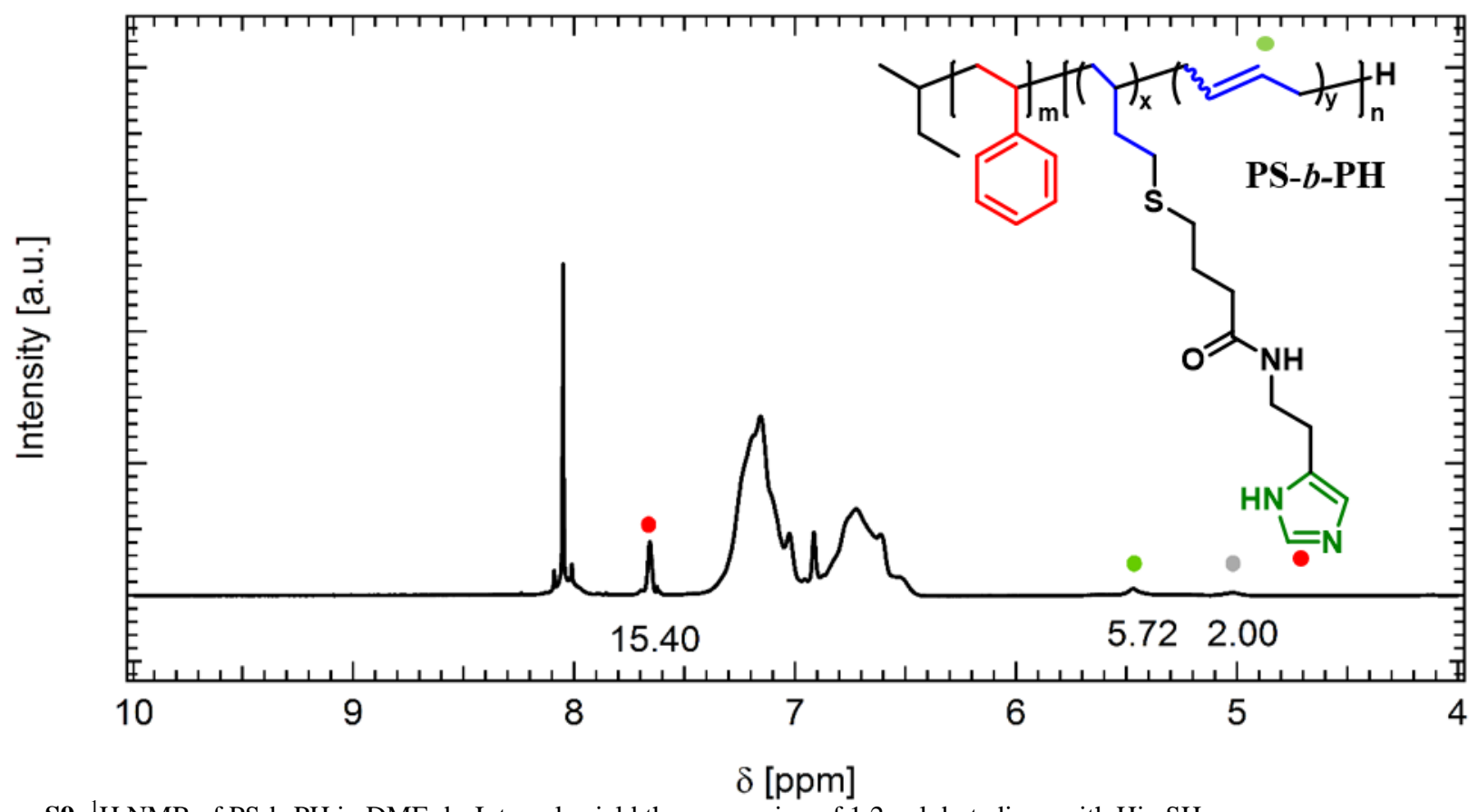

Figure S9: ${ }^{1} \mathrm{H}$ NMR of PS-b-PH in DMF-d $\mathrm{d}_{7}$. Integrals yield the conversion of 1,2 polybutadiene with His-SH. 


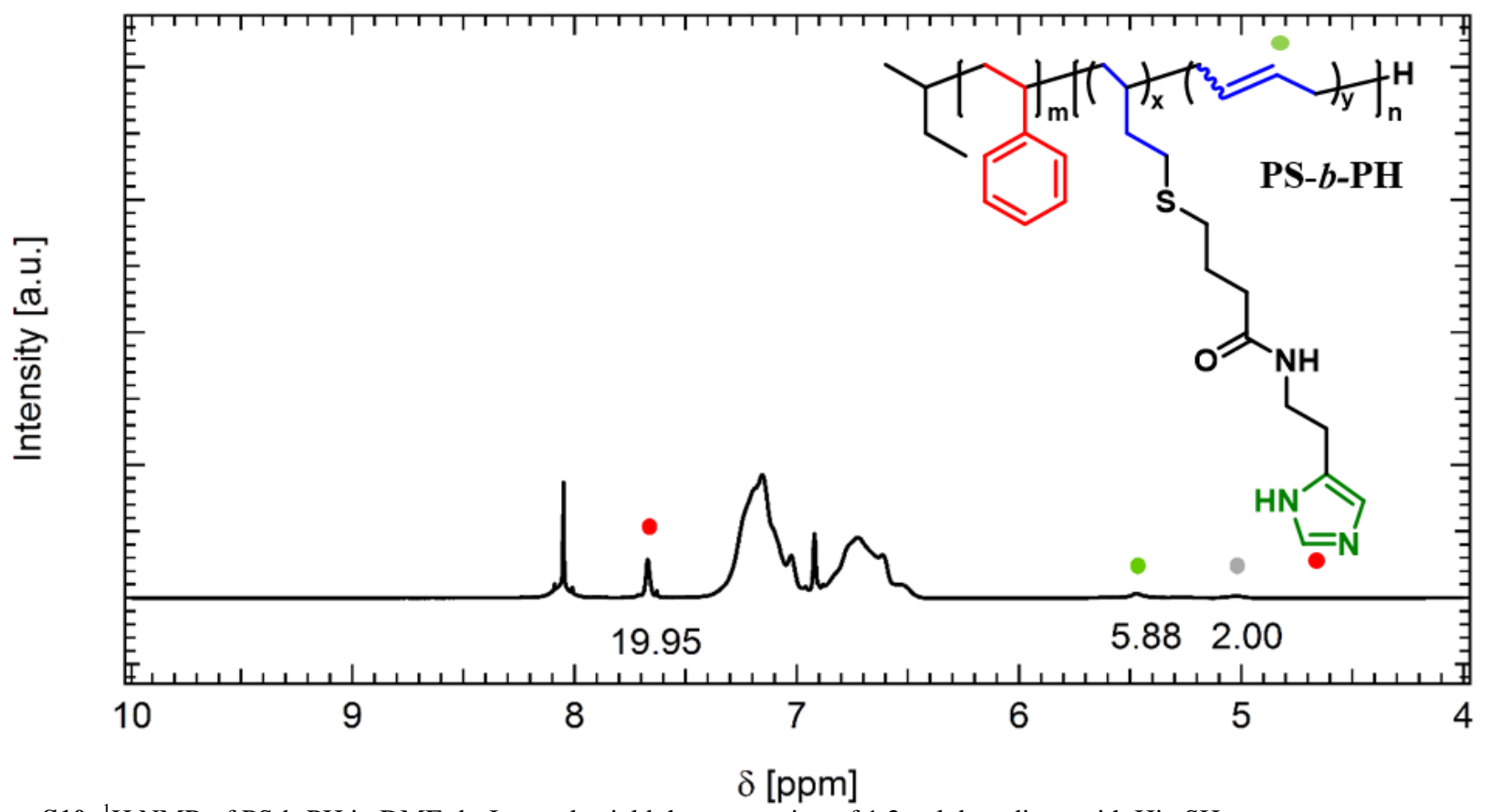

Figure S10: ${ }^{1} \mathrm{H}$ NMR of PS-b-PH in DMF-d . Integrals yield the conversion of 1,2 polybutadiene with His-SH.

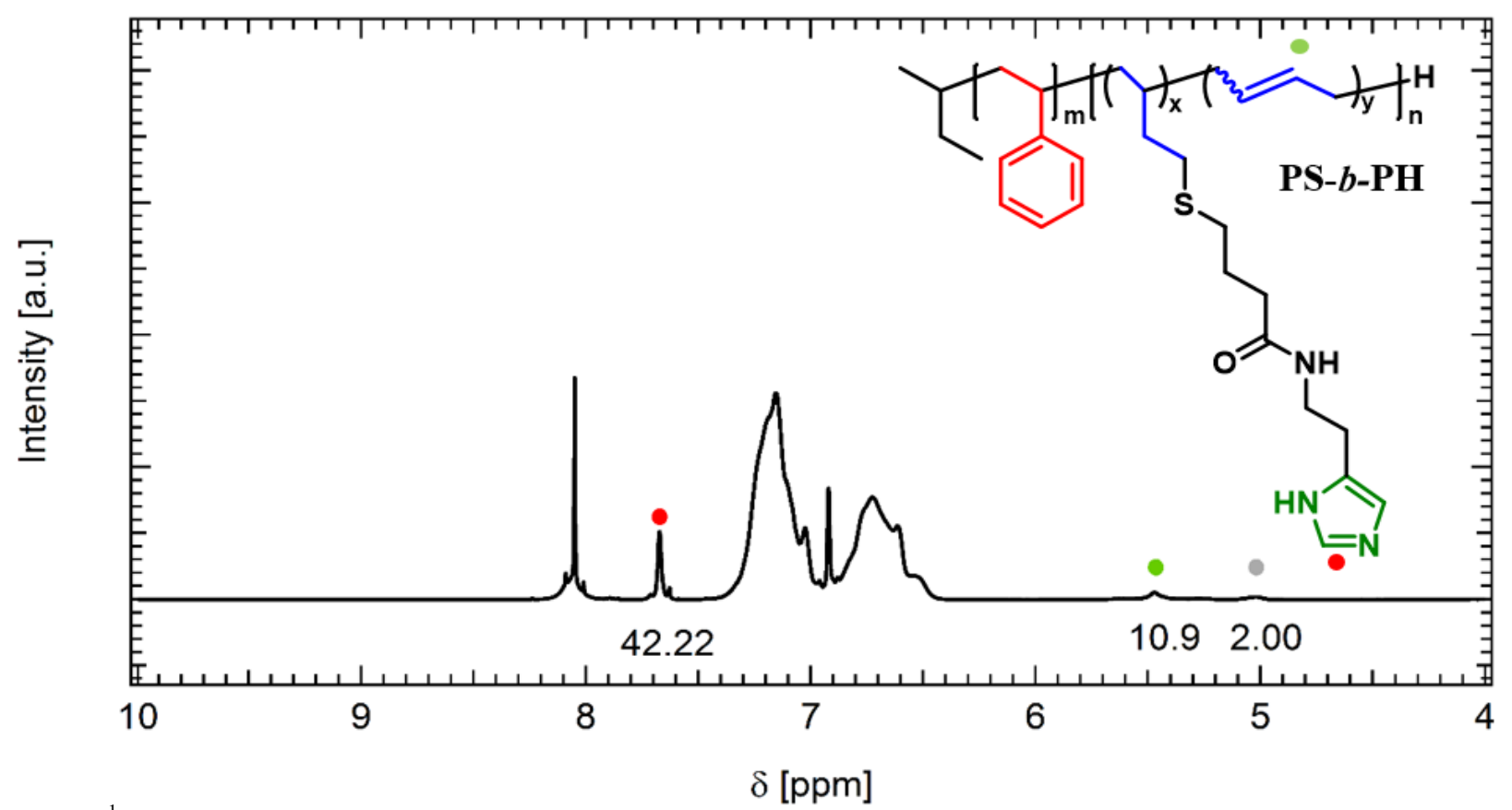

Figure S11: ${ }^{1} \mathrm{H}$ NMR of PS-b-PH in DMF- $\mathrm{d}_{7}$. Integrals yield the conversion of 1,2 polybutadiene with His-SH. 


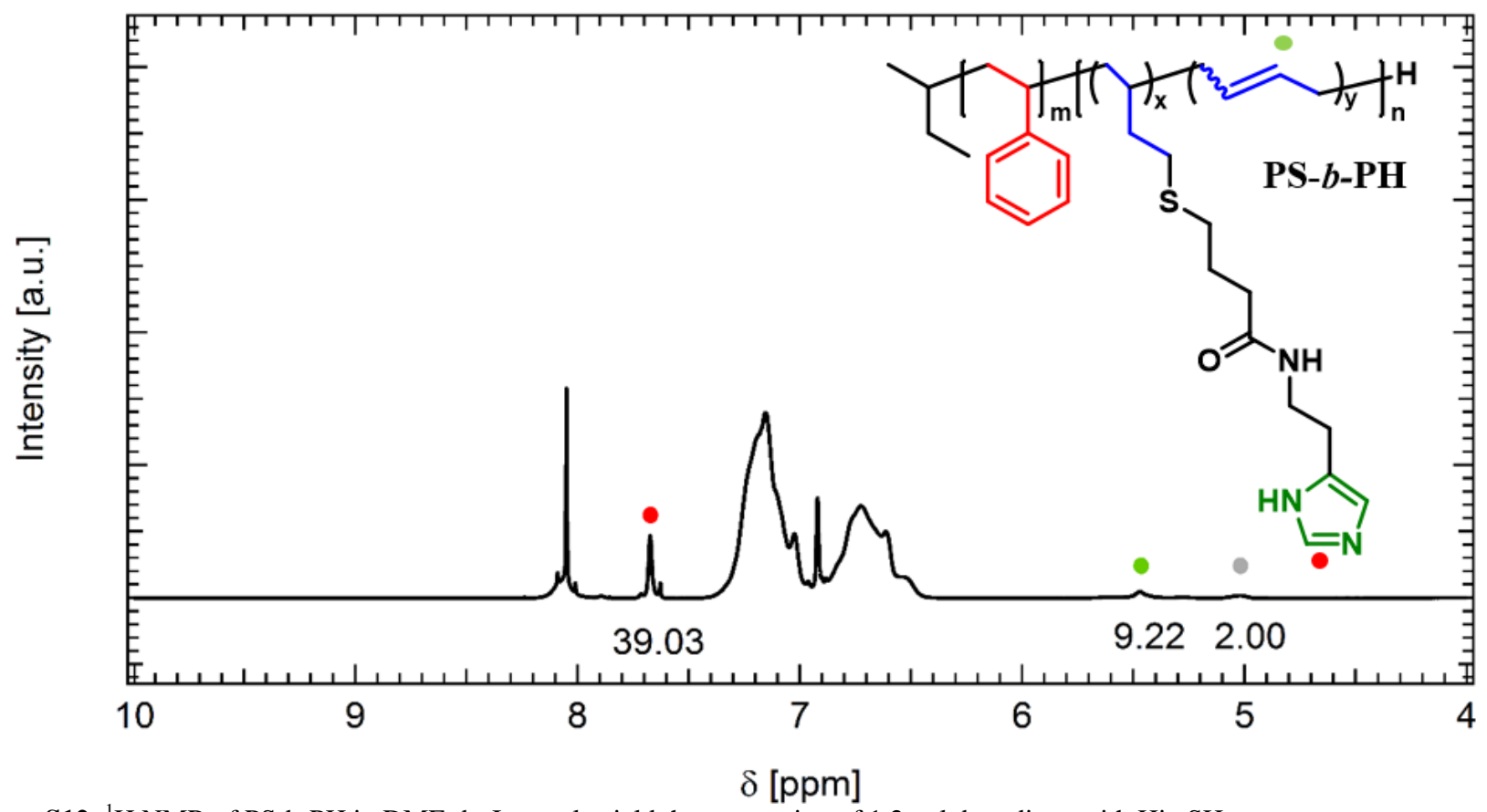

Figure S12: ${ }^{1} \mathrm{H}$ NMR of PS-b-PH in DMF- $\mathrm{d}_{7}$. Integrals yield the conversion of 1,2 polybutadiene with His-SH.

Table S2: Properties of PS- $b$-PH as determined from ${ }^{1} \mathrm{H}$ NMR

$\begin{array}{ccccc}\text { Polymer }^{\mathrm{a}} & \text { \% Conversion } & \mathrm{N}_{\mathrm{S}} & \mathrm{N}_{\mathrm{H}} & \mathrm{N}_{\mathrm{B}} \\ \text { SH22.7 } & 93.9 & 108 & 24 & 8 \\ \text { SH37.0 } & 95.2 & 213 & 51 & 16 \\ \text { SH51.5 } & 97.50 & 327 & 83 & 24 \\ \text { SH63.5 } & 98.0 & 413 & 107 & 27\end{array}$

${ }^{a}$ Polymers are labeled SHXX.X, where XX.X is the lamellar domain spacing in nm of hydrated PS- $b$-PIL membranes at room temperature derived from the corresponding PS- $b$-PH precursor.

\section{Physical Characterization of Dry PS-b-PIL}

Elemental analysis of SIL22.7 yields: $74.15 \% \mathrm{C}, 7.01 \% \mathrm{H}, 2.84 \% \mathrm{~N}$, and $6.34 \% \mathrm{~F}$, as determined by Elemental Analysis, Inc. This result is consistent with that anticipated from ${ }^{1} \mathrm{H}$ NMR: $72.39 \% \mathrm{C}, 6.98 \% \mathrm{H}, 4.84 \% \mathrm{~N}$, and $6.56 \% \mathrm{~F}$.

Elemental analysis of SIL51.5 yields: $72.71 \% \mathrm{C}, 7.08 \% \mathrm{H}, 3.01 \% \mathrm{~N}$, and $7.70 \% \mathrm{~F}$, as determined by Elemental Analysis, Inc. This result is consistent with that anticipated from ${ }^{1} \mathrm{H}$ NMR: $70.64 \% \mathrm{C}, 6.89 \% \mathrm{H}, 5.27 \% \mathrm{~N}$, and $7.15 \% \mathrm{~F}$. 


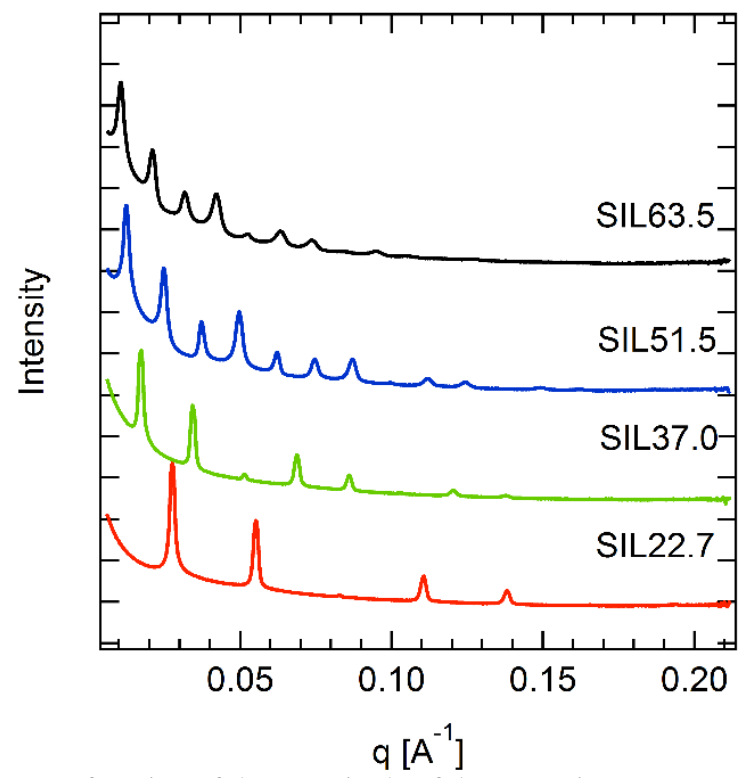

Figure S13: SAXS intensity profiles as a function of the magnitude of the scattering vector q. PS- $b$-PIL with varying number of segments $\mathrm{N}$ access lamellar morphologies with tunable domain spacing. Profiles are offset for clarity. SAXS data collected on dry PS- $b$-PIL membranes at room temperature.

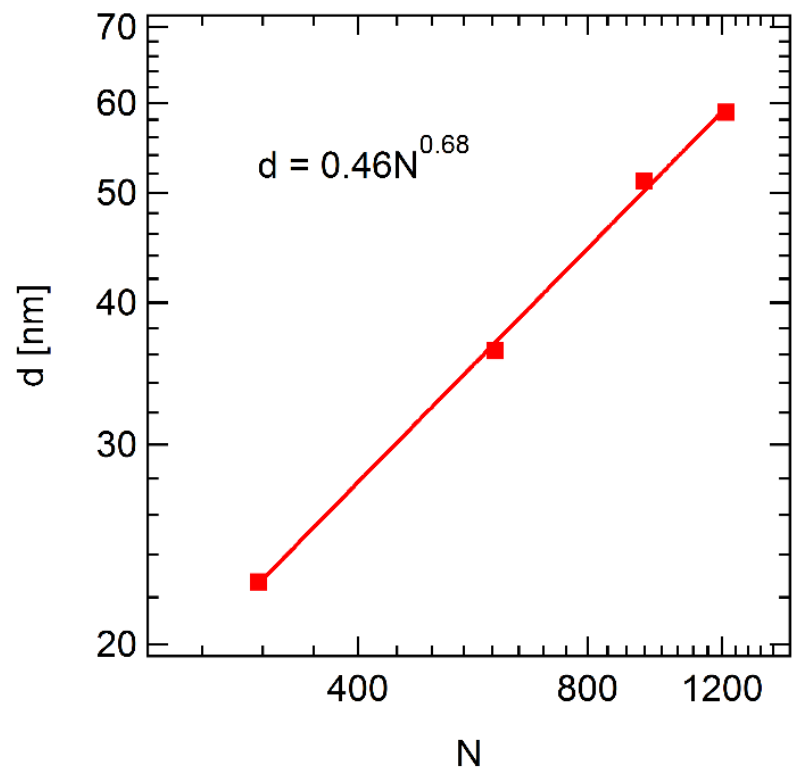

Figure S14: Variation of lamellar domain spacing $d$ as a function of chain length $\mathrm{N}$. The scaling $\mathrm{d} \sim \mathrm{N}^{0.68}$ demonstrates a degree of chain stretching consistent with that predicted in the strong segregation limit.

Table S3: Calculation of lamellar domain spacing of Block Copolymers based on PS-b-PIL

$\begin{array}{ccccccc}\text { Polymer }^{\mathrm{a}} & \mathrm{q}^{*}\left(\mathrm{~nm}^{-1}\right)^{\mathrm{b}} & \mathrm{q}^{2^{*}}\left(\mathrm{~nm}^{-1}\right)^{\mathrm{c}} & \mathrm{q}^{3 *}\left(\mathrm{~nm}^{-1}\right)^{\mathrm{c}} & \mathrm{q}^{4^{*}}\left(\mathrm{~nm}^{-1}\right)^{\mathrm{d}} & \mathrm{d}(\mathrm{nm})^{\mathrm{e}} & \text { Morphology } \\ \text { SIL22.7 } & 0.276 & 0.552 & - & 1.106 & 22.7 & \text { LAM } \\ \text { SIL37.0 } & 0.172 & 0.344 & - & 0.688 & 36.5 & \text { LAM } \\ \text { SIL51.5 } & 0.124 & 0.248 & 0.373 & 0.497 & 50.7 & \text { LAM } \\ \text { SIL63.5 } & 0.105 & 0.210 & 0.317 & 0.421 & 59.8 & \text { LAM }\end{array}$

${ }^{a}$ Polymers are labeled SILXX.X, where XX.X is the lamellar domain spacing in nm of hydrated PS- $b$-PIL membranes at room temperature. ${ }^{b}$ Determined from the primary scattering peak of the SAXS profiles. ${ }^{b}$ Determined from the second order scattering 
peak of the SAXS profiles. ${ }^{\mathrm{c}}$ Determined from the third order scattering peak of the SAXS profiles. ${ }^{\mathrm{d}}$ Determined from the fourth order scattering peak of the SAXS profiles. ${ }^{e}$ Determined using the following equation: $d=\frac{2 \pi}{q^{*}}$

\section{Physical Characterization of Hydrated PS- $b$-PIL}

Table S4: Calculation of volume fractions of Block Copolymers based on Protic PILs

$\begin{array}{cccccc}\text { Polymer }^{\mathrm{a}} & \mathrm{M}_{\mathrm{n}}(\mathrm{kg} / \mathrm{mol})^{\mathrm{b}} & v\left(\mathrm{~nm}^{3}\right)^{\mathrm{c}} & v_{\mathrm{S}}\left(\mathrm{nm}^{3 \mathrm{~d}}\right) & v_{\mathrm{B}}\left(\mathrm{nm}^{3}\right)^{\mathrm{e}} & \mathrm{f}_{\mathrm{IL}} \\ \text { SIL22.7 } & 20.8 & 29.6 & 17.82 & 0.888 & 0.37 \\ \text { SIL37.0 } & 42.5 & 60.5 & 35.15 & 1.78 & 0.39 \\ \text { SIL51.5 } & 66.6 & 94.8 & 53.96 & 2.66 & 0.40 \\ \text { SIL63.5 } & 85.3 & 121.4 & 68.15 & 3.00 & 0.41\end{array}$

${ }^{a}$ Polymers are labeled SILXX.X, where XX.X is the lamellar domain spacing in nm of hydrated PS- $b$-PIL membranes at room temperature. ${ }^{b}$ Determined via ${ }^{1} \mathrm{H}$ NMR end-group analysis. ${ }^{c}$ Determined using a density of $1.167 \mathrm{~g} / \mathrm{cm}^{3}$ as measured with a helium AccuPyc II 1340 Pycnometer. ${ }^{\mathrm{d} D e t e r m i n e d ~ u s i n g ~ a ~ p o l y s t y r e n e ~ m o n o m e r ~ v o l u m e ~ o f ~} 0.165 \mathrm{~nm}^{3} .{ }^{1}{ }^{\mathrm{e}}$ Determined using a polybutadiene monomer volume of $0.111 \mathrm{~nm}^{3}$. $^{2}$

Table S5: Calculation of lamellar domain spacing of Block Copolymers based on Protic PILs

$\begin{array}{ccccc}\text { Polymer }^{\mathrm{a}} & \mathrm{q}^{*}\left(\mathrm{~nm}^{-1}\right)^{\mathrm{b}} & \mathrm{q}^{2^{*}}\left(\mathrm{~nm}^{-1}\right)^{\mathrm{c}} & \mathrm{d}(\mathrm{nm})^{\mathrm{d}} & \text { Morphology } \\ \text { SIL22.7 } & 0.278 & 0.553 & 22.7 & \text { LAM } \\ \text { SIL37.0 } & 0.168 & 0.339 & 37.0 & \text { LAM } \\ \text { SIL51.5 } & 0.120 & 0.239 & 51.5 & \text { LAM } \\ \text { SIL63.5 } & 0.099 & 0.200 & 63.5 & \text { LAM }\end{array}$

${ }^{a}$ Polymers are labeled SILXX.X, where XX.X is the lamellar domain spacing in nm of hydrated PS- $b$-PIL membranes at room temperature. ${ }^{b}$ Determined from the primary scattering peak of the SAXS profiles. ${ }^{b}$ Determined from the second order scattering peak of the SAXS profiles. ${ }^{c}$ Determined using the following equation: $d=\frac{2 \pi}{q^{*}}$

Table S6: Calculation of the ionic conductivity of Block Copolymers based on Protic PILs

$\begin{array}{cccccc}\text { Polymer }^{\mathrm{a}} & \mathrm{L}(\mathrm{cm}) & \mathrm{t}(\mu \mathrm{m}) & \mathrm{W}(\mathrm{cm}) & \mathrm{R}(\mathrm{k} \Omega)^{\mathrm{b}} & \sigma \times 10^{-4}(\mathrm{~S} / \mathrm{cm})^{\mathrm{c}} \\ \text { SIL22.7 } & 0.350 & 165 & 1.30 & 56.7 & 2.90 \\ \text { SIL37.0 } & 0.350 & 210 & 1.16 & 34.2 & 4.20 \\ \text { SIL51.5 } & 0.350 & 197 & 1.30 & 42.9 & 3.20 \\ \text { SIL63.5 } & 0.350 & 203 & 1.04 & 57.6 & 2.90\end{array}$

${ }^{a}$ Polymers are labeled SILXX.X, where XX.X is the lamellar domain spacing in nm of hydrated PS- $b$-PIL membranes at room temperature. ${ }^{b}$ Determined from the high $\mathrm{x}$-intercept of a Nyquist plot (i.e., negative imaginary part of the complex impedance, Z", versus the real part of the impedance, $Z$ '). ${ }^{c}$ Determined using the following equation: $\sigma=\frac{\mathrm{L}}{\mathrm{RWt}}$

Table S7: Calculation of water uptake of Block Copolymers based on Protic PILs

$\begin{array}{cccccccc}\text { Polymer }^{\mathrm{a}} & \mathrm{m}_{\text {dry }}(\mathrm{mg}) & \mathrm{m}_{\text {wet }}(\mathrm{mg}) & \mathrm{m}_{\text {water }}(\mathrm{mg}) & \begin{array}{c}\%_{\text {water }} \\ \mathrm{n}_{\text {water }} \times 10^{-5} \\ (\mathrm{~mol})^{\mathrm{b}}\end{array} & \begin{array}{r}\mathrm{n}_{\text {IL }} \times 10^{-5} \\ (\mathrm{~mol})^{\mathrm{c}}\end{array} & \lambda \\ \text { SIL22.7 } & 71.5 & 87.3 & 15.8 & 18.1 & 87.8 & 8.43 & 10 \\ \text { SIL37.0 } & 67.4 & 81.7 & 14.3 & 17.5 & 79.4 & 7.95 & 10 \\ \text { SIL51.5 } & 72.6 & 87.9 & 15.3 & 17.4 & 84.9 & 8.57 & 10 \\ \text { SIL63.5 } & 58 & 69.7 & 11.7 & 16.8 & 64.9 & 6.84 & 9\end{array}$

${ }^{a}$ Polymers are labeled SILXX.X, where XX.X is the lamellar domain spacing in nm of hydrated PS- $b$-PIL at room temperature. ${ }^{b}$ Determined from the molecular weight of water $18.02 \mathrm{~g} / \mathrm{mol}$. ${ }^{\mathrm{c}}$ Determined from the mass fraction $(45 \mathrm{wt} \%)$ and the molecular weight $381.41 \mathrm{~g} / \mathrm{mol}$ of ionic moieties. 


\section{Estimation of Grain Size using Scherrer Analysis}

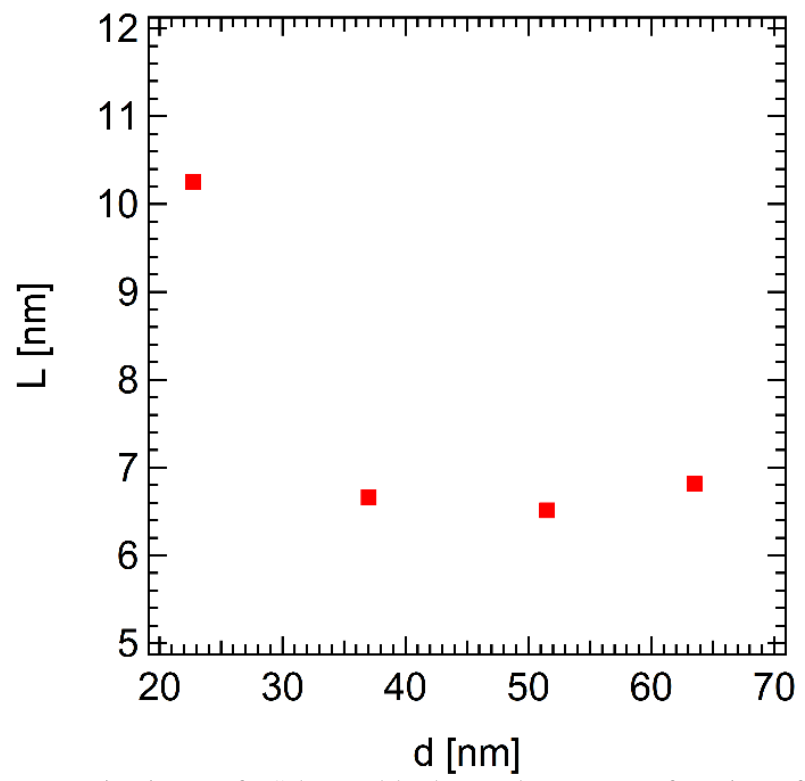

Figure S15: Variation of Scherrer grain size L of PS-b-PIL block copolymers as a function of domain spacing d. PS- $b$-PIL hydrated membranes exhibit a decrease in grain size with domain spacing that readily plateaus at $37.0 \mathrm{~nm}$. Notice that the grain size estimated with the Scherrer formalism is a lower bound, as demonstrated by L values that are not physical because they satisfy the relationship $\mathrm{L}<\mathrm{d}$ over the range of domain spacing investigated.

The full width at half maximum (FWHM) of the primary scattering peak yields an

estimate of grain size (L) through the Scherrer formalism (i.e., $L=\frac{2 \pi}{F W H M}$ ), and is anticipated to increase with chain length due to the longer timescales required by high molecular weight block copolymers to self-assemble into an equilibrium lamellae nanostructure with long-range order and well-defined domain spacing. This is a lower bound on grain size because factors such as instrumentation, temperature, and lattice imperfections contribute significantly to the scattering peak profile $^{3,4}$. Therefore, the length scale estimated from the FWHM represents an average over the distribution of grain sizes and shapes in a nanostructured material without a straightforward relationship to that measured using electron microscopy ${ }^{5}$ and birefringence ${ }^{6}$. Even though, PS- $b$ PIL exhibit a decrease in Scherrer grain size with chain length that readily plateaus at $37.0 \mathrm{~nm}$, the values of $\mathrm{L}$ are not physical as revealed by the relationship $\mathrm{L}<\mathrm{d}$ over the range of domain spacing investigated. We argue that a more methodical analysis that isolates the contribution of 
grain size to the peak width is necessary to elucidate the effect of grain size on the ionic conductivity of block copolymer membranes based on hydrated protic polymerized ionic liquids.

\section{References}

1. Richardson, M. J.; Savill, N. G. Volumetric properties of polystyrene: influence of temperature, molecular weight and thermal treatment. Polymer 1977, 18, (1), 3-9.

2. $\quad$ Eitouni, H.; Balsara, N., Thermodynamics of Polymer Blends. In Physical Properties of Polymers Handbook, Mark, J., Ed. Springer New York: 2007; pp 339-356.

3. Langford, J. I.; Wilson, A. J. C. Scherrer after sixty years: A survey and some new results in the determination of crystallite size. Journal of Applied Crystallography 1978, 11, (2), 102113.

4. $\quad$ Roe, R.-J., Methods of X-ray and Neutron Scattering in Polymer Science. Oxford University Press: New York, 2000.

5. $\quad$ Ryu, H. J.; Fortner, D. B.; Lee, S.; Ferebee, R.; De Graef, M.; Misichronis, K.; Avgeropoulos, A.; Bockstaller, M. R. Role of Grain Boundary Defects During Grain Coarsening of Lamellar Block Copolymers. Macromolecules 2013, 46, (1), 204-215.

6. Balsara, N. P.; Garetz, B. A.; Dai, H. J. Relationship between birefringence and the structure of ordered block copolymer materials. Macromolecules 1992, 25, (22), 6072-6074. 